Review (Narrative)

\title{
Application of Shape Memory Alloy
}

\author{
Eva Clithy, Ph.D.
}

\section{SUMMARY}

Shape memory alloy (SMA) is a special metal material with unique properties, that is, this material can restore to its original shape through pressure or temperature changes after deformation. The successful development of Ti-Ni SMA in the 1960s, with the continuous deepening of SMA theory and application research, SMAs gradually entered the practical stage. At present, SMAs have been widely used in aerospace, biomedicine, mechanical electronics and other fields. This article briefly reviews the application of SMAs and makes perspective comments on the current problems of SMA research.

\section{KEYWORDS}

Shape Memory Alloy; Ti-Ni Alloy; Materials; Application

Sci Insigt. 2020; 33(3):167-174. doi:10.15354/si.20.re072.
Author Affiliations: Author affiliations are listed at the end of this article.

Correspondence to: Dr. Eva Clithy, Ph.D., Division of Biology and Chemistry, The BASE, Chapel Hill, NC 27510, USA.

Email: eva.clithy@basehq.org. 
HAPE memory alloy (SMA) refers to a type of alloy with a certain initial shape that is plastically deformed at low temperature and fixed into another shape, and then restored to the original shape by heating above a certain critical temperature alloy. The function that SMA can remember its original shape is called shape memory effect (SME). As a special new functional material, SMA is a smart material that integrates perception and drive. Because of its unique function, it can produce small and exquisite, highly automated, reliable performance components and attracted attention, and has been widely used.

\section{DEVELOPMENT HISTORY AND STATUS QUO OF SHAPE MEMORY ALLOYS}

The discovery of SME in metals can be dated back to the 1930s. In 1938, Greningerh and Mooradian of the United States discovered the thermoelastic transformation of martensite in $\mathrm{Cu}-\mathrm{Zn}$ alloy. Subsequently, Kurdiumov of the former Soviet Union studied this phenomenon. In 1951, Chang and Read observed in an Au-47:5at\% Cd alloy with an optical microscope that the martensite interface moved with temperature. This was the first report to observe the SME of metals. A few years later, Burkhart observed the same phenomenon in In-Ti alloys. However, at the time, the discovery of these phenomena was only regarded as a special phenomenon of individual material and failed to arouse enough attention. It was not until 1963 that Buehler et al. of the US Naval Ordnance Laboratory discovered that Ti-Ni alloys with equal atomic ratios had excellent shape memory functions and successfully developed a shape memory alloy "Nitinol" with practical value. Since then, the research on SMAs has entered a completely new stage (1).

In 1969, Raychem first applied pipe joints made of $\mathrm{Ni}-\mathrm{Ti}$ alloy to the US F14 fighter jet. In 1970, NASA used Ti-Ni memory alloy wire and used it into a spaceship antenna. These applications greatly stimulated the international research and development of SMAs. In the 1970s, Ni-Ti-based, Cu-Al-Ni-based, and Cu-Zn-Albased SMAs were successively developed; in the 1980s, Fe-Mn-Si-based, stainless steel-based, and other ironbased SMAs were developed. These alloys have been attracting great interest from material workers due to their low cost and easy processing. From the 1990s to the present, high-temperature SMAs, wide hysteresis memory alloys, and memory alloy films have become research hotspots (2).

In the early 1980s, researchers broke through the difficulties in the study of $\mathrm{Ti}-\mathrm{Ni}$ alloys. Since then, SMAs have been widely used in various fields. There have been more than 10,000 technique patents related to SMA applied in a variety of countries, and hundreds of examples have been put into the market. At the same time, with the rise of research on smart materials and smart institutions, the application of SMA has been pushed into a wider field. At present, the number of scientific papers related to SMA research has ranked first in the field of martensitic transformation, and the application fields involved in such materials are extremely extensive. So far, more than 10 series of more than 50 varieties of SMAs have been widely used in various industries such as electronics, machinery, energy, medical, aerospace, automotive, home appliances and construction.

\section{APPLICATION OF SHAPE MEMORY ALLOY}

So far, there have been more than 20 kinds of alloy systems with shape memory effect, but the practical applications are limited to $\mathrm{Ti}-\mathrm{Ni}$ and $\mathrm{Cu}-\mathrm{Zn}-\mathrm{Al}$ alloy systems (Cu-Al-Ni and Fe-Mn-Si Department of memory alloys are also under development and application). At present, SMAs are widely used in the fields of electronics, machinery, energy, aerospace, civil engineering, automotive, medical, and daily life $(3,4)$ (Table 1$)$.

\section{Connecting Fastener}

Using the excellent shape memory effect of Ni-Ti alloys, various connection fasteners can be made, such as pipe joints, fastening rings, connection sleeves and fastening rivets.

\section{Pipe Joint}

The SMA connector has a simple structure, light weight, small space occupation, high safety, easy disassembly, stable and reliable performance, and has been widely used in the fields of aerospace, aviation, electronics and mechanical engineering. Among them, the pipe joint is one of the most successful applications of shape memory alloys. The use method of the pipe joint is shown in 


\section{Table 1. Application Examples of Shape Memory Alloys.}

Disposable Use in Industry

\begin{tabular}{ll}
\hline Fasteners & Combination of Printed Circuit Board \\
\hline Pipe Joint & Welding of Integrated Circuits \\
\hline Antennas for Space Vehicles & Connector Splint for Electrical Appliances \\
\hline Fire Alarm & Sealing Rings \\
\hline Reusable in Industry & Thermal Energy Conversion Device \\
\hline Temperature Sensors & Control Elements of Thermoelectric Relays \\
\hline Thermostat for Adjusting Indoor Temperature & Pen Drive for Recorders \\
\hline Shutters for Greenhouse Windows & Manipulators, Robots \\
\hline Clutch for Automobile Radiator Fan & \\
\hline Medical Use & Fixed Splint for Fracture Site \\
\hline Filters to Eliminate Clotting Thrombus & Arched Metal Wires for Orthodontics \\
\hline Orthopedic Rod & Artificial Tooth Roots \\
\hline Clips for Brain Aneurysm Surgery & Artificial Joints \\
\hline Valve of Artificial Heart and Artificial Kidney & \\
\hline
\end{tabular}

Figure 1 (5). The outer diameter of the pipe to be connected is $\varphi$; after the one-way memory treatment of the $\mathrm{Ti}-\mathrm{Ni}$ alloy with an inner diameter of $\varphi(1-4 \%)$, use a cone at low temperature $\left(<\mathrm{M}_{\mathrm{f}}\right)$. The die is expanded to make its diameter $\varphi(1+4 \%)$. The lubricant used for the expansion can be a polyethylene film; insert the to-beconnected pipe from both ends of the pipe joint at a low temperature. Remove the insulation material and wait for the temperature of its pipe joint to rise to room temperature. Since the inner diameter of SME is restored to the size before expansion, the tight connection of the pipeline is realized.

\section{Fastening Rivets}

Rivets and bolts are usually used for fastening in engineering, but in some occasions (such as in a sealed vacuum), it is difficult to operate, and SMA fastening rivets can easily achieve this kind of fastening. As shown in Figure 2 (6), the tail of the rivet is shaped like an opening. Before tightening, cool the rivet in dry ice and straighten the tail, insert it into the hole of the fastener, the temperature rises to restore the shape, and the rivet tail can be tightened by splitting the tail. In addition, the shape memory alloy connecting fasteners that have been put into practical use also include the sealing ring of the thin-walled tube and the head, the fastening screw, the nut, and the bearing positioning ring.

\section{Satellite Antenna}

Satellite antenna is one of the most typical application examples of shape memory alloy (11). The antenna is made of Ti-Ni alloy, which is processed into a parabolic antenna in the state of the alloy matrix, and then cooled to below the Mf point to generate martensite. This type of martensite is easily deformed, so the antenna can be folded and crumpled into small groups and placed in the satellite. After the satellite enters space orbit, the alloy wire is heated by heating or using solar energy. Once the temperature reaches $77^{\circ} \mathrm{C}\left(>\mathrm{A}_{\mathrm{f}}\right)$, the alloy wire folded into small clusters undergoes a reverse phase change and opens completely, returning to the original parabolic antenna shape.

\section{Regulator}

Using SMA to restore shape when heated, its restoring force can do work to the outside, and it can be made into various driving adjustment elements. This type of driving mechanism integrates temperature sensing and driving into one, with simple structure, high sensitivity 


\section{Figure 1. Schematic Diagram of the Use of Shape Memory Alloy Pipe Joints.}

A

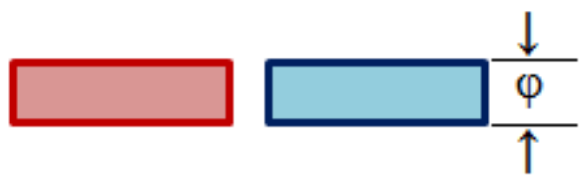

D

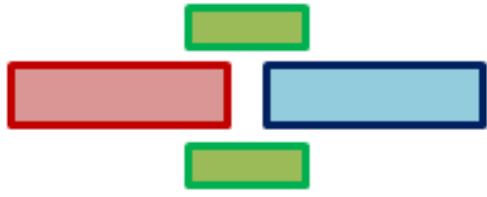

B
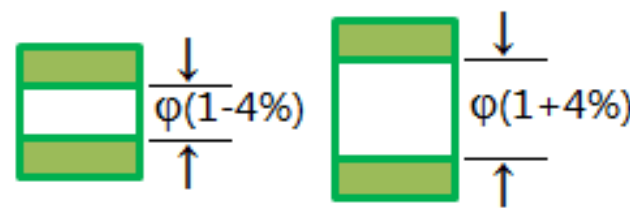

E

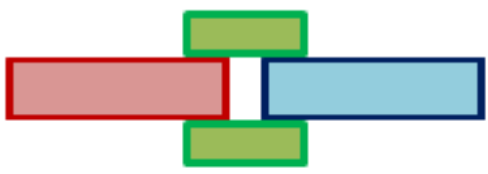

A. Pipelines waiting to be connected; B. Memory pipe joint; C. Post-expansion of the diameter; D. Before SMA casing connection; E. Connected tightly after heating.

\section{Figure 2. Schematic Diagram of the Use of Shape Memory Alloy Fastening Rivets.}

A
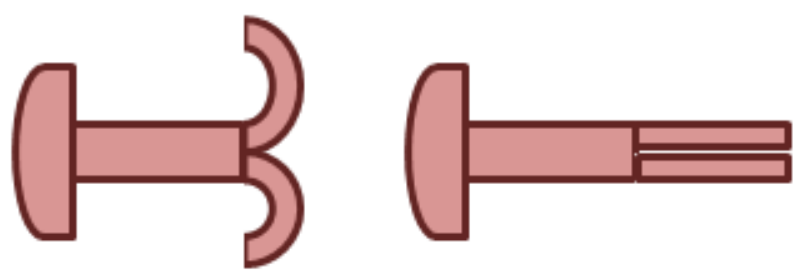

C

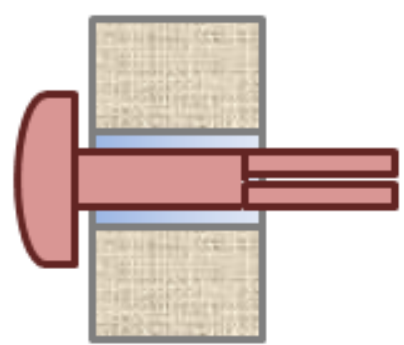

D

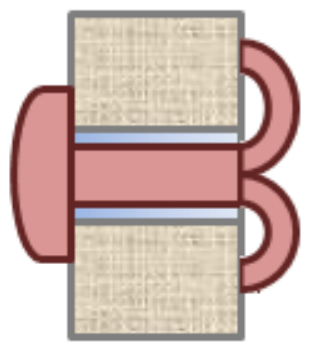




\section{Figure 3. The Thermostat Driven by the Memory Alloy.}

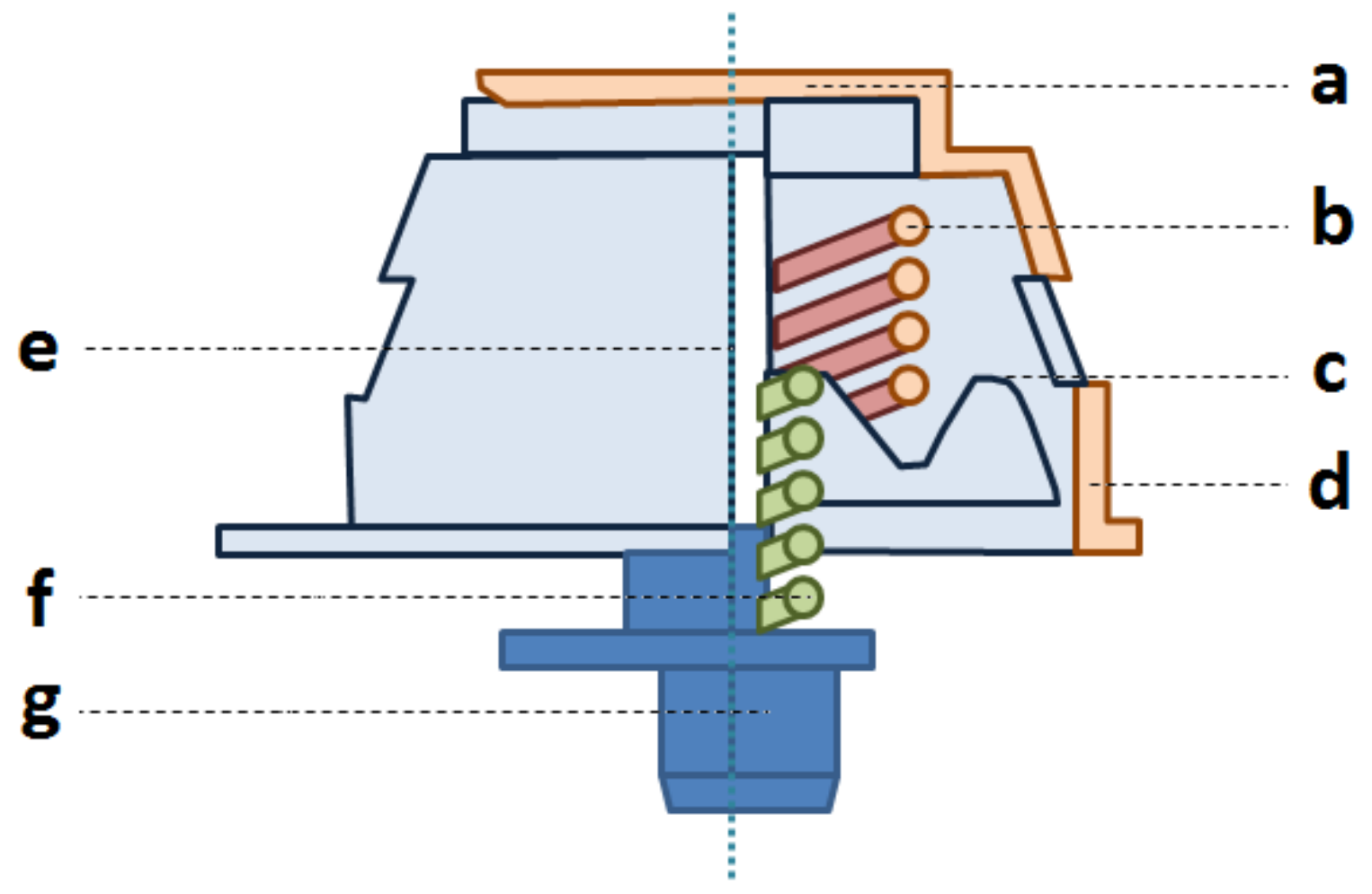

a. Main valve; b. Return spring; c. Sub-valve; d. Housing; e. Push rod; $f$. Spring seat; g. Memory alloy element.

and good reliability. It has always been one of the research hotspots of scientific researchers $(8,9)$. Figure 3 shows the SMA thermostat used in automobiles (10). The temperature range of the most efficient automobile engine is $60-80{ }^{\circ} \mathrm{C}$. When the actual temperature is higher than this temperature, the SMA spring expands and compresses the bias spring to open the circulating water cooling system; when the temperature is low, the bias spring force is greater than the memory The alloy spring forces and compresses the memory alloy spring, turning off the circulating water cooling system. SMA thermostat has the advantages of long life and stable driving.

\section{Manipulator}

The shape memory element has the dual functions of temperature sensing and driving, so it can be used to make robots and manipulators to change the action through temperature changes. Figure 4 depicts a micromanipulator with 5 degrees of freedom of shoulder, elbow, wrist and finger (11). The fingers and wrists rely on the expansion and contraction of the Ti-Ni alloy coil spring to realize opening and closing and bending movements, and the elbows and shoulders rely on the extension and contraction of the linear $\mathrm{Ti}-\mathrm{Ni}$ alloy wire to achieve bending movements. Each shape memory alloy element is controlled by the pulse width adjustable current directly connected. The biggest feature of this manipulator is its miniaturization. Another important feature is its soft movement, which is very close to the movement of the human hand. It can complete the work of removing paper cups that have fallen into the water. In addition to the 5-degree-of-freedom manipulator, Japan has also developed 13-degree-of-freedom and 17-degree-of-freedom manipulators in recent years.

\section{Medical Applications}




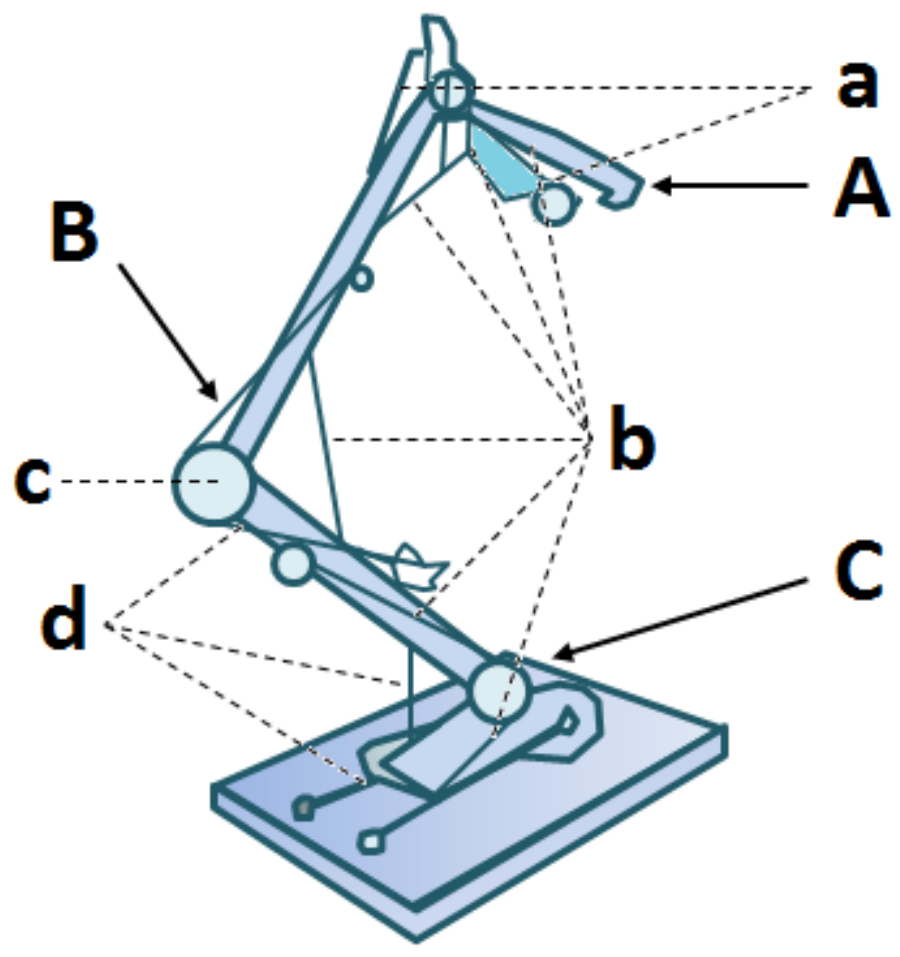

A. Fingers; B. Elbow; C. Shoulder; a. Ti-Ni alloy spiral spring; b. Bias spring; c. Valve-tightening wheel; d. Ti-Ni alloy wire. Manipulator weight: $50 \mathrm{~g}$; Manipulator height: $15 \mathrm{~cm}$.

As a new type of intelligent material, SMA is also very active in the medical field. So far, the main application fields of shape memory alloys in medicine include the following.

(i) Dentistry (only contact with the surface of the living body).

(ii) Plastic surgery (transplanted in a living body, in contact with living tissue for a long time)

(iii) Spare parts of medical instruments (without direct contact with biological tissues).

In addition to the required shape memory or superelastic properties, the SMA used in the medical field must also meet the reliability requirements of chemistry and biology. Generally, the metal implanted in the living body will dissolve to form metal ions in the environment of biological fluids, some of which will cause various cytotoxic reactions such as carcinogenicity, chromosomal aberration, etc. or cause thrombosis, that is, the material is more biocompatible difference. Therefore, only alloys that form a passivation film with strong stability after being in contact with living organisms can be implanted in living organisms. After many experiments, it was confirmed that only Ti-Ni alloy can satisfy the abovementioned conditions in the existing practical memory alloys (12). Therefore, Ti-Ni alloy is the only SMS currently used in medicine. Because Ti-Ni alloy has peculiar shape memory effect, good biocompatibility, super elasticity and excellent wear resistance and good corrosion resistance. Therefore, it has been widely used in clinical medicine and medical equipment (13).

\section{PERSPECTIVE}


In the research and application of SMA, there are still many problems to be solved (11), for example: (i) Because the various functions of SMA are dependent on the martensite phase transformation, they need to be continuously heated, cooled and loaded, Unloading, and the material changes have hysteresis, so SMA is only suitable for low-frequency (below $10 \mathrm{~Hz}$ ) narrow-band vibration, which greatly limits the application of materials. (ii) SMA itself has defects such as damage and cracks. How to overcome these defects and improve the performance of materials is an urgent problem that needs to be solved. (iii) The existing SMA mechanism model still has some defects in practical engineering applications. How to overcome these shortcomings, so as to accurately simulate the material behavior of SMA is also an important topic that needs to be studied; (iv) In medical applications, continue to study the biocompatibility and cytotoxicity of SMA. (v) As a new type of functional material, SMA's processing and preparation processes are difficult to control. At present, there is no SMA automatic production line, and the material cost is also quite expensive. (vi) To improve the application level, SMA components also need to be further minia- turized to improve the response speed and control accuracy.

There is still much work to be done in this regard. The future development direction and trend of SMA research can be summarized in the following aspects: (i) fully explore, improve and perfect the performance of existing SMA; (ii) research and develop new alloy materials with shape memory effect; (iii) SMA film Research and application; (iv) Research and development of SMA intelligent composite materials; (v) Development of high-temperature SMA.

\section{CONCLUSION}

In sum, as a new type of functional material, SMA has the unique advantages that other materials are difficult to replace, and the application prospect is very broad. In the future, as the basic theoretical research of SMA becomes more mature and the application development efforts continue to increase, new application fields will surely be explored.

\section{ARTICLE INFORMATION}

Author Affiliations: Division of Biology and Chemistry (DBC) (Clithy), The BASE, Chapel Hill, NC 27157, USA.

Author Contributions: Dr. Clithy has full access to all of the data in the study and takes responsibility for the integrity of the data and the accuracy of the data analysis.

Study concept and design: Clithy.

Acquisition, analysis, or interpretation of data: Clithy.

Drafting of the manuscript: Clithy.
Critical revision of the manuscript for important intellectual content: Clithy. Statistical analysis: N/A.

Obtained funding: N/A.

Administrative, technical, or material support: Clithy.

Study supervision: Clithy.

Conflict of Interest Disclosures: The author declared no competing interests of this manuscript submitted for publication.

Funding/Support: None.
Role of the Funder/Sponsor: N/A.

How to Cite This Paper: Clithy E. Application of Shape Memory Alloy. Sci Insigt. 2020; 33(3):167-174.

Digital Object Identifier (DOI): http://dx.doi.org/ 10.15354/si.20.re072.

Article Submission Information: Received, March 02, 2020; Revised: March 25, 2020; Accepted: May 10, 2020.

\section{REFERENCES}

1. Buehler WJ, Gilfrich JV, Wiley RC. Effect of low-temperature phase changes on the mechanical properties of alloys near composition TiNi. J Appl Phys 1963; 34(5):1475-1477.

2. Chluba C, Ge W, Lima de Miranda R, Strobel J, Kienle L, Quandt E, Wuttig M. Shape memory alloys. Ultralowfatigue shape memory alloy films. Science 2015; 348(6238):1004-1007.

3. Lendlein A, Kelch S. Shape-memory polymers. Angew Chem Int Ed Engl 2002; 41(12):2035-2057.

4. Gandhi Y, Pirondi A, Collini L. Optimal design of shape memory alloy compositeunder deflection constraint. Materials (Basel) 2019; 12(11):1733.

5. Jee KK, Han JH, Jang WY. A method of pipe joining using shape memory alloys. Mater Sci Eng A 2006; 438440:1110-1112.

6. Kim JS, Lee DY, Koh JS, Jung GP,
Cho KJ. Component assembly with shape memory polymer fastener for microrobots. Smart Mater Struct 2014; 23:5011.

7. Kalra S, Bhattacharya B, Munjal B. Design of shape memory alloy actuated intelligent parabolic antenna for space applications. Smart Mater Struct 2017; 26(9):14.

8. Huang W. On the selection of shape memory alloys for actuators. Mater 
Design 2002; 23:11-19.

9. 9 Pasquale M. Mechanical sensors and actuators. Sensor Actuat BChem 2003; A106:142-148.

10. Huang BJ, Wang JH, Wu JH, Yang PE. A fast response heat pump water heater using thermostat made from shape memory alloy. Appl Therm Eng 2009; 29(1):56-63.

11. Gull MA, Bai SP, Bak T. A review on design of upper limb exoskeletons. Robotics 2020; 9:16.

12. Gil FJ, Planell JA. Shape memory alloys for medical applications. Proc
Inst Mech Eng H 1998; 212(6):473488.

13. Tarniţă D, Tarniţă DN, Bîzdoacă N, Mîndrilă I, Vasilescu M. Properties and medical applications of shape memory alloys. Rom J Morphol Embryol 2009; 50(1):15-21. 